\title{
The impact of technical parameters on the perception quality of three-dimensional content
}

\author{
Fabijan Nushi, Vladimir Cviljušac, Lidija Mandić \\ Faculty of Graphic Arts, University of Zagreb, Croatia
}

\begin{abstract}
The growth of three-dimensional visualizations and information is increasing over time, and in addition to that, technology is offering new methods, i.e. models and ways of meeting the needs of visual communication. When using the rotating linear screen, for the best results, it is necessary to be familiar with the real performance of the device. The parameters tested on forty examinees are distance, the angle of view and the impact of the background colour. The purpose was to define the optimal parameters for the device to provide visual information. The conducted test has shown that the devices have a smaller view angle than stated and that the distance needs to be greater because of low resolution and low pixel density on the screen surface, which results in small unilluminated gaps that create unwanted lines during the projection. The effect that the background has on the 3D simulation of the hologram has also been tested and it was determined that the black background in comparison to the white one is much better, as the contrast is more pronounced.
\end{abstract}

Keywords: 3D hologram simulation, view angle, image quality, contrast

\section{Introduction}

In today's society, with the development of new technology, the need for three-dimensional information [1] arises and with that the representation of 3D holographic simulation, which is achieved with a rotating linear screen. It uses the persistence of vision [2] in order to achieve a three-dimensional effect.

The growth of three-dimensional visualizations and information is increasing over time; in addition to that, technology is offering new methods, i.e. models and ways of meeting the needs of visual communication. Threedimensional holographic displays with all the novelties and updates that offer more are progressively used in the $3 \mathrm{D}$ information displays, which can be used in various areas such as manufacturing, mechanical engineering, pharmaceutical industry, medicine, telecommunication and many more. The possibilities are endless.

An interesting characteristic of the 3D hologram simulation (unlike 3D television or virtual reality) is the fact that no additional tools (3D or VR glasses) [3] are needed to be able to see it, which is an advantage when it comes to exhibitions, fairs or any interactive events. The best results are achieved when the limit and the potential of the device is well known. The quality of the 3D holographic simulation depends on many external factors (e.g. lighting) and the shape of the surrounding space. It is necessary to improve the quality of the display, or to be more exact, the transmission of information. Regarding space, the quality varies depending on the device's distance and how it is placed. The difference between what the eye sees and what the mind is aware of can create an unusually long period of attentiveness, which is a great way of creating positive emotions in consumers allowing them to memorize information about the object observed. So far in the early stages of scientific research, these are the factors involved: the number of rotations of the linear screen, the number of images per second, the pixel density needed to achieve the 1080 pixel (p) resolution [4].

At the same time, the need for the exceptional quality of the visual information is increasing over time. The necessity for this type of 
research has appeared because of an enormous application of this technology in creative visualizations. The goal was to study how the distance, the visual angle and two contrasting backgrounds (white and black) influence the quality of the projection and how to attain the optimal parameters in order to achieve excellent results in this type of visual communication, which can be used in creative installations. Taking into consideration the length of the linear display, which is $43 \mathrm{~cm}$ $\left(17^{\star} 2,54 \mathrm{~cm}\right)$, the defined distances, from which the visual information was observed, were set based on the guidelines [5].

The examinees who participated in the research were observing the projection of the logo (green) of the Faculty of Graphic Arts in Zagreb.

The need for this type of research arose as a consequence of the use of the rotating linear display for creative purposes, in an attempt to emphasize climate change awareness [6].

\section{Experimental part}

Two rotating linear displays have been used in the research (3D Hologram led fan), which produce the 3D holographic simulation, with the RGB diodes attached to the blades of the linear display. On both screens, we can see the visual of the Faculty of Graphic Arts (figure 1).

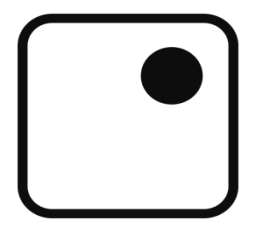

Figure 1. The logo of the Faculty of Graphic Arts

The main goal was to determine the optimal quality of perception taking in consideration the distance and the angle of the 3D holographic display, but also to determine whether the background has an impact on the visual and the quality of the $3 \mathrm{D}$ holographic simulation.

The experiment set up, shown in figure 2, consists of a protractor with a span of $0^{\circ}$ to $180^{\circ}$. The rotating linear display is set on the horizontal line of the protractor, with the starting point of $0^{\circ}$.

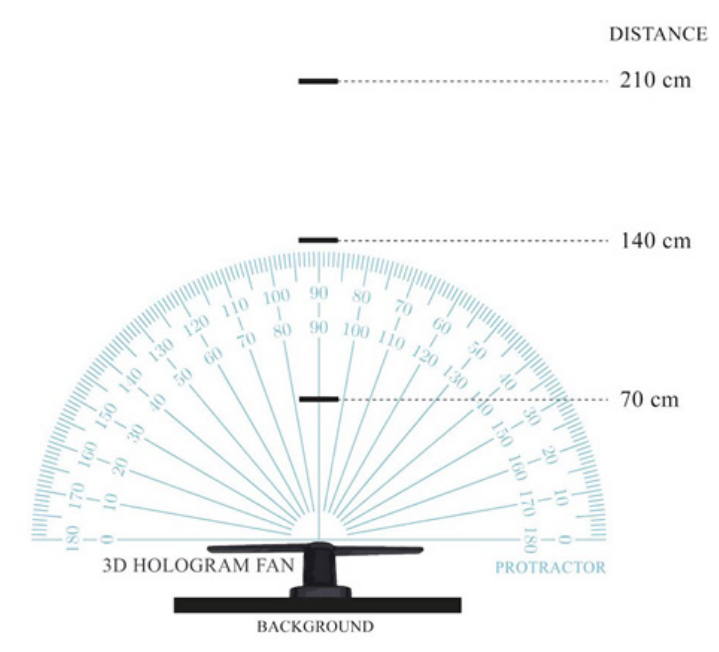

Figure 2. Experiment setup

In the introduction of the questionnaire basic questions are asked, the examinees' sex, age, education, whether they are wearing prescription glasses and/or contacts or whether they are visually impaired in any way (protanopia, daltonism, astigmatism, etc.)

While inspecting the distance, the examinees were viewing the $3 \mathrm{D}$ holographic simulation from three different distances, $70 \mathrm{~cm}, 140 \mathrm{~cm}$ and $210 \mathrm{~cm}$ (shown in figure 3). From each distance, it was required to determine the quality of the display from 1 to 5 , according to Likert scale [7].

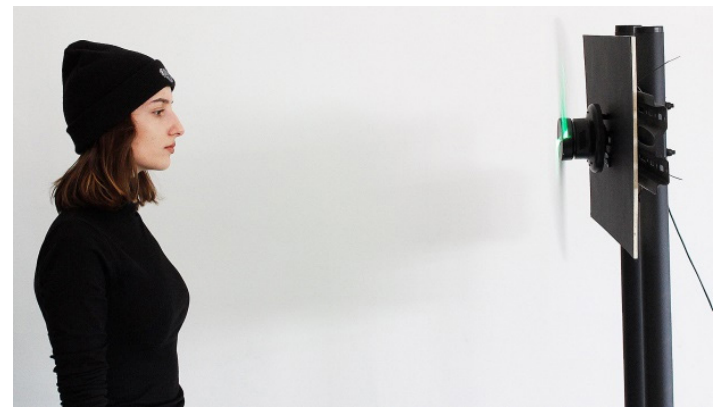

Figure 3. Determining the quality of the 3D effect from a $70 \mathrm{~cm}$ distance

The devices were placed on a vertical stand $(180 \mathrm{~cm})$, while the protractor $(250 \mathrm{~cm} \mathrm{x} 130$ $\mathrm{cm}$ ) was placed on the floor. The rotating linear displays are fixated onto two different backgrounds, black and white (shown in figure 4 and 5). The dimensions of the backgrounds are determined by the size of the display, which is $43 \mathrm{~cm} \times 50 \mathrm{~cm}$. 


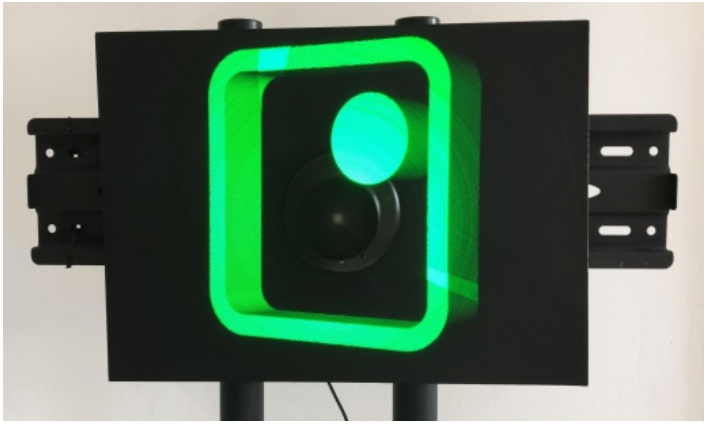

Figure 4. The 3D holographic simulation using a black background

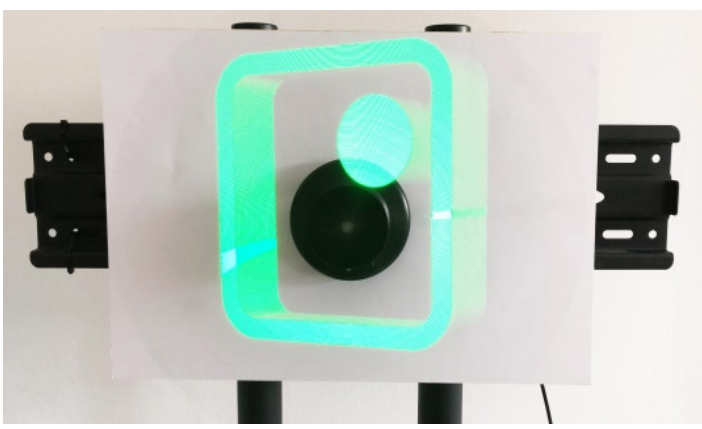

Figure 5. The 3D holographic simulation using a white background

In order to determine the angle of view, the examinees estimated the quality of the $3 \mathrm{D}$ holographic simulation by observing the white and black background from various angles.

The viewing area is limited to the front of the hologram display, from $0^{\circ}$ to $180^{\circ}$, making it impossible to observe the $3 \mathrm{D}$ image from $180^{\circ}$ to $360^{\circ}$ due it not volume display [8], shown on figure 6 . The display of the $3 \mathrm{D}$ simulation changes depending on the point of view. The examinees shifted alongside the protractor, starting from $0^{\circ}$, step of moving was $10^{\circ}$ and then finalizing at the finish point of $180^{\circ}$.

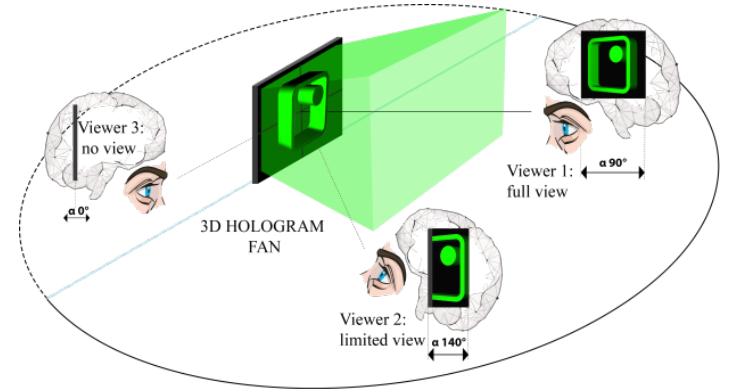

Figure 6. Observing the simulation at different angles

\section{Research results / Discussion of results}

There were 40 examinees in total participating in this research, of which $53.5 \%$ (21) were women and $47.5 \%$ (19) were men. The majority of the examinees were 23-year-old students, of which $52.5 \%$ wear reading glasses or contacts and $15 \%$ of them have astigmatism. The diagonal of the holographic linear display is $43 \mathrm{~cm}\left(17^{\star} 2,54 \mathrm{~cm}\right)$, and the device can be compared with the diagonal of the screen, for which a $70 \mathrm{~cm}$ viewing distance [5] is recommended. In comparison to the full HD resolution $1920 \times 1080$ pixels [9], the resolution is three times smaller, which is the reason why the research was conducted from three different distances. Due to low resolution $640 \times 640$ pixels, the linear display of 43 $\mathrm{cm}\left(17^{\star} 2,54 \mathrm{~cm}\right)$ lacks pixel density which results in small unilluminated gaps, creating unwanted lines during the projections. If observed from a greater distance, the lines are less noticeable. In figure 7 the results of the research are presented, meaning the best perception quality of the holographic simulation is achieved when the viewers are at a $210 \mathrm{~cm}$ distance.

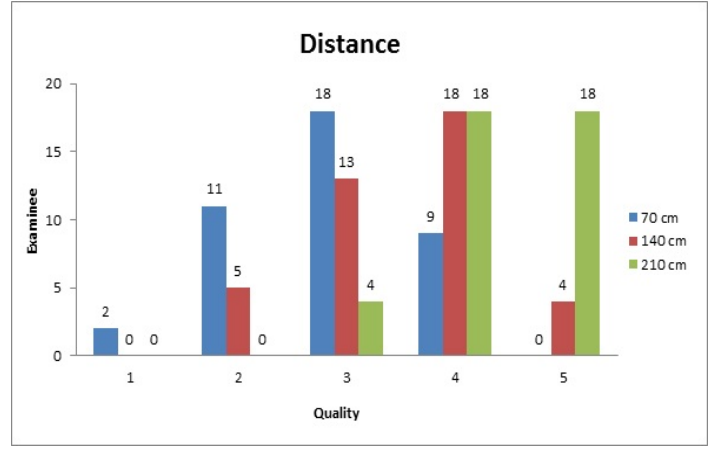

Figure 7. Subjective image quality assesment for different distances

When examining the angle of view, the results have shown that the $3 \mathrm{D}$ holographic display is not noticeable when it comes to bordering angles $\left(140^{\circ}-180^{\circ}\right.$ and $\left.0^{\circ}-40^{\circ}\right)$, meaning the examinees have labelled it as not good enough quality, grading as poor and bad on the rating scale. At viewing angles $40^{\circ}$ to $60^{\circ}$ and $120^{\circ}$ to $140^{\circ}$ examinees rated image quality as fair. The highest perceived image quality (good and 
The impact of technical parameters on the perception quality of three-dimensional content

excellent) for $90 \%$ of examinees was at angles between $60^{\circ}$ and $120^{\circ}$. In the specifications defined by the manufacturer, the view angle was $160^{\circ}$, but results show that the view angle is smaller $\left(100^{\circ}\right)$.

A T-test compared the arithmetic means of the variables and observed whether there is a significant statistical difference in the evaluation of the quality of the $3 \mathrm{D}$ simulations under certain angles.

Using this statistical method the results were grouped because they did not show a significant statistical difference. The angles were separated into 7 sections, which can be seen in table 1 , where $B$ denotes black background and $\mathrm{W}$ white background.

Table 1. Division of angles into groups

\begin{tabular}{|c|c|}
\hline Segments & Viewing angles \\
\hline B1/W1 & $180^{\circ}-160^{\circ}$ \\
\hline B2/W2 & $150^{\circ}-130^{\circ}$ \\
\hline B3/W3 & $120^{\circ}-100^{\circ}$ \\
\hline B4/W4 & $90^{\circ}$ \\
\hline B5/W5 & $80^{\circ}-60^{\circ}$ \\
\hline B6/W6 & $50^{\circ}-30^{\circ}$ \\
\hline B7/W7 & $20^{\circ}-0^{\circ}$ \\
\hline
\end{tabular}

The results of descriptive statistics are shown in table 2. Based on these results the angular Gaussian distribution is created for both backgrounds (black and white), as shown in figures 8 and 9 .
Table 2. Statistical information for various angles and their backgrounds

\begin{tabular}{|l|c|c|c|c|c|}
\hline \multicolumn{7}{|c|}{ Descriptive Statistics } \\
\hline & N & $\begin{array}{c}\text { Mini- } \\
\text { mum }\end{array}$ & $\begin{array}{c}\text { Maxi- } \\
\text { mum }\end{array}$ & Mean & $\begin{array}{c}\text { Std. } \\
\text { Deviation }\end{array}$ \\
\hline Black 1 & 40 & 1,00 & 1,33 & 1,1583 &, 16858 \\
Black 2 & 40 & 1,67 & 4,67 & 3,1417 &, 79488 \\
Black 3 & 40 & 2,67 & 5,00 & 4,6833 &, 48305 \\
Black 4 & 40 & 4,00 & 5,00 & 4,9750 &, 15811 \\
Black 5 & 40 & 2,33 & 5,00 & 4,7083 &, 51853 \\
Black 6 & 40 & 2,00 & 4,33 & 3,1250 &, 63014 \\
Black 7 & 40 & 1,00 & 1,33 & 1,0833 &, 14618 \\
White 1 & 40 & 1,00 & 1,67 & 1,1000 &, 17213 \\
White 2 & 40 & 1,67 & 4,33 & 2,7833 &, 67326 \\
White 3 & 40 & 3,00 & 5,00 & 4,4667 &, 58373 \\
White 4 & 40 & 3,00 & 5,00 & 4,8250 &, 50064 \\
White 5 & 40 & 3,00 & 5,00 & 4,6083 &, 51134 \\
White 6 & 40 & 1,67 & 4,00 & 2,9833 &, 64472 \\
White 7 & 40 & 1,00 & 1,33 & 1,0667 &, 13503 \\
Valid N & 40 & & & & \\
(listwise) & & & & & \\
\hline
\end{tabular}

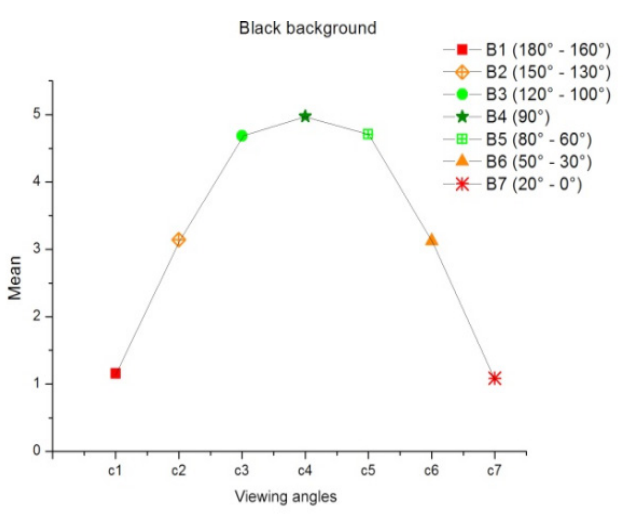

Figure 8. Gaussian distribution for the black background

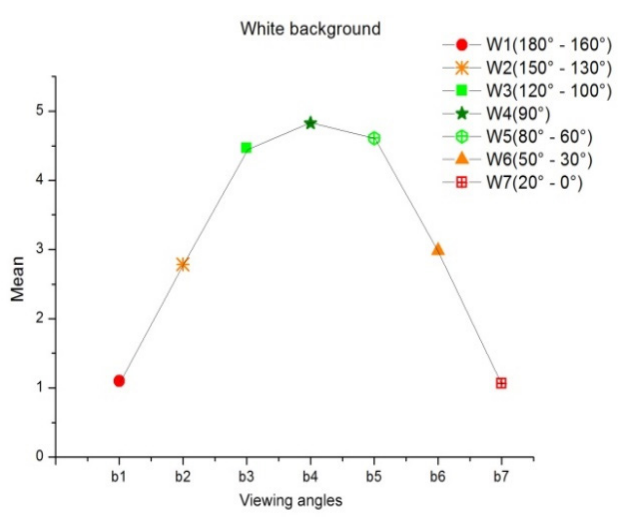

Figure 9. Gaussian distribution for the white background 
The data shown in table 3 show statistical difference between the quality of images viewed at angle $\left(\mathrm{W} 4=90^{\circ}\right.$ and $\mathrm{W} 5 / \mathrm{B} 5=60^{\circ}$ to $80^{\circ}$ ).

Table 3. Representation of the isolated symmetrical angles

\begin{tabular}{|c|c|c|c|c|c|c|}
\hline \multicolumn{7}{|c|}{ One-Sample Test } \\
\hline & \multicolumn{6}{|c|}{ Test Value $=4,975$} \\
\hline & \multirow[t]{2}{*}{$\mathrm{t}$} & \multirow[t]{2}{*}{$\mathrm{df}$} & \multirow[t]{2}{*}{$\begin{array}{l}\text { Sig. } \\
\text { (2-ta- } \\
\text { lied) }\end{array}$} & \multirow[t]{2}{*}{$\begin{array}{l}\text { Mean } \\
\text { Differe- } \\
\text { ne }\end{array}$} & \multicolumn{2}{|c|}{$\begin{array}{c}\text { 95\% Confidence } \\
\text { Interval of the } \\
\text { Difference }\end{array}$} \\
\hline & & & & & Lower & Upper \\
\hline B5 & $-3,253$ & 39 & 002 &,- 26667 &,- 4325 &,- 1008 \\
\hline W4 & $-1,895$ & 39 & ,066 &,- 15000 &,- 3101 & ,0101 \\
\hline W5 & $-4,535$ & 39 &, 000 &,- 36667 &,- 5302 &,- 2031 \\
\hline
\end{tabular}

The results show is that there is a significant difference in assessing the quality of the 3D hologram between $\mathrm{C} 1 / \mathrm{B} 1\left(160^{\circ}-180^{\circ}\right)$ and $\mathrm{C} 7 / \mathrm{B} 7\left(0^{\circ}-20^{\circ}\right)$ because when it comes to these angles the $3 \mathrm{D}$ simulation cannot be perceived. When it comes to $\mathrm{C} 2 / \mathrm{B} 2\left(150^{\circ}\right.$ $\left.130^{\circ}\right)$ and $\mathrm{C} 6 / \mathrm{B} 6\left(50^{\circ}-30^{\circ}\right)$ the simulation is of better quality in comparison to the previous one. Furthermore, the quality of the simulation when it comes to $\mathrm{C} 3 / \mathrm{B} 3\left(120^{\circ}-100^{\circ}\right)$ and $\mathrm{C} 5 /$ B5 $\left(80^{\circ}-60^{\circ}\right)$ in comparison to the rest of the categories is considerably improved. Lastly, the simulation is best seen with a central angle $\mathrm{C} 4 / \mathrm{B} 4\left(90^{\circ}\right)$ shown in figure 10.

Out of all the data processed there is not a significant statistical difference between the simulation quality regarding which background is used.

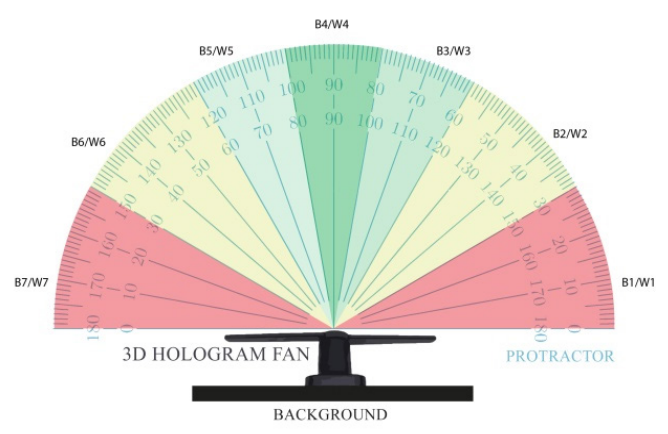

Figure 10. Visual representation of the different angles and their quality

Although there is not a significant statistical difference, a visual assessment has shown that the $3 \mathrm{D}$ simulation is better perceived on a black background. The results showed that some examinees reported discomfort, caused by the low resolution of the rotating linear display and the small unilluminated gaps, due to low pixel density [10].

\section{Conclusion}

This research consisted of a qualitative assessment of the technical parameters of the rotating linear screen (3D Hologram LED fan) such as the view angle and the distance. The goal was to improve the $3 \mathrm{D}$ holographic simulations when it comes to creative expression. The impact of the two backgrounds on the whole experience has been tested as well. It was found that black background, rather than the white one, provides a better experience since the contrast provides a clearer image. The optimal perception of the holographic simulation is achieved between $60^{\circ}$ and $120^{\circ}$. To achieve the best perception of the simulation the optimal distance is $210 \mathrm{~cm}$. The reason behind that is a lower resolution, causing gaps and lines to form on the simulation, which is a consequence of a low pixel density. When observing from a greater distance the unwanted effect is less noticeable. Future research will be focused on examining technical parameters with the goal of achieving a maximized perception quality with the technical abilities of the device.

\section{References}

1. Hall, J. (2017). How Augmented Reality Is Changing The World Of Consumer Marketing. Retrieved November 12, 2018, from https://www.forbes. com/sites/forbesagencycouncil/2017/11/08/howaugmented-reality-is-changing-the-world-ofconsumer-marketing/

2. M Bach, CM Poloschek "Optical Illusions "- Adv Clin Neurosci Rehabil, 2006 - dfisica.ubi.pt

3. McGlade, A. (2015). Augmented Reality Without The Glasses. Retrieved November 12, 2018, from https://www.forbes.com/sites/alanmcglade/ 2015/02/08/augmented-reality-without-the-glasses/

4. https://unlimited.hamk.fi/teknologia-ja-liikenne/ holographic-fan-case-study/

5. Mijović B. : Primjenjena ergonomija, Veleučilište u Karlovcu, Karlovac 2008.; ISBN 978-953-7343-23-1 
The impact of technical parameters on the perception quality of three-dimensional content

6. Nushi F. (2018), Primjena novih tehnologija u kreativne svrhe (vizualizaciji)

7. John M. Linacre "Optimizing Rating Scale Category Effectiveness", MESA Psychometric Laboratory, University of Chicago, Journal of Applied Measurement 3:1 2002 p.85-106.

8. Jason Geng "Three-dimensional display technologies", IEEE Intelligent Transportation Systems Society, doc. ID 188297

9. Jing Li, Yao Koudota, Marcus Barkowsky, Hélène Primon, Patrick Le Callet "Comparing upscaling algorithms from HD to Ultra HD by evaluating preference of experience“, Published in: 2014 Sixth International Workshop on Quality of Multimedia Experience (QoMEX), DOI: 10.1109/ QoMEX.2014.6982320

10. Lackner, J. (2014). Motion sickness: more than nausea and vomiting. Experimental Brain Research 8/2014. Retrieved November 12, 2018, from https://doi.org/10.1007/s00221-014-4008-8 